\title{
Role of growth hormone-releasing hormone in sleep and growth impairments induced by upper airway obstruction in rats
}

\author{
A. Tarasiuk*, ${ }^{*}$, N. Berdugo-Boura*,\#, , A. Troib ${ }^{\#}$ and Y. Segev",
}

ABSTRACT: Upper airway obstruction (UAO) can lead to abnormal growth hormone (GH) homeostasis and growth retardation but the mechanisms are unclear. We explored the effect of UAO on hypothalamic GH-releasing hormone (GHRH), which has a role in both sleep and GH regulation.

The tracheae of 22-day-old rats were narrowed; UAO and sham-operated animals were sacrificed 16 days post-surgery. To stimulate slow-wave sleep (SWS) and GH secretion, rats were treated with ritanserin (5- $\mathrm{HT}_{2}$ receptor antagonist). Sleep was measured with a telemetric system. Hypothalamic GHRH, hypothalamic GHRH receptor (GHRHR) and GH receptor, and orexin were analysed using ELISA, real-time PCR and Western blot.

UAO decreased hypothalamic GHRH, GHRHR and GH receptor levels, while orexin mRNA increased $(p<0.01)$. In UAO rats, the duration of wakefulness was elevated and the duration of SWS, paradoxical sleep and slow-wave activity was reduced $(p<0.001)$. Ritanserin alleviated these effects, i.e. normalised hypothalamic GHRH content, decreased wake duration, increased duration and depth of SWS, and attenuated growth impairment $(p<0.001)$.

Here, we present evidence that growth retardation in UAO is associated with a reduction in hypothalamic GHRH content. Our findings show that abnormalities in the GHRH/GH axis underlie both growth retardation and SWS-disorder UAO.

KEYWORDS: Growth hormone axis, growth retardation, rat, sleep, upper airway loading

hildren with upper airway obstruction (UAO) usually suffer from sleep-disordered breathing and growth retardation [1-4]. We previously hypothesised that the impairment of growth is related to reduced growth hormone $(\mathrm{GH})$ release from the pituitary gland, which normally requires undisturbed slow-wave sleep (SWS) [1]. The release of $\mathrm{GH}$ is greatly enhanced during sleep, especially early in the night; this is associated with the appearance of delta waves on electroencephalography, which are characteristic of SWS [5], and increased release of GHreleasing hormone (GHRH) in the hypothalamus [6]. The mutual relationships between sleep and GHRH are complex. Central or systemic administration of exogenous GHRH enhances non-rapid eye movement (NREM) sleep, while inhibition of endogenous GHRH secretion suppresses sleep duration and depth [7-9]. Genetic mutations associated with GHRH deficiency lead to reduction of both depth and duration of NREM sleep and to a decrease in GH secretion, resulting in dwarfism [9].
The possibility that GHRH may be affected in children with sleep-disordered breathing emerges from studies showing that both slow-wave activity, a quantitative measure for NREM sleep depth [10], and GH axis are suppressed [1]. Moreover, all these sleep and hormonal disturbances, as well as growth retardation, are reversed following surgical removal of the UAO $[1,2,10]$. In adult humans, GH and slow-wave activity are normalised following treatment of sleep-disordered breathing with continuous positive airway pressure [11, 12].

Ritanserin, a selective $5-\mathrm{HT}_{2}$ receptor antagonist, increases endogenous $\mathrm{GH}$ release and NREM sleep [13]. The strong association between sleep and $\mathrm{GH}$ release raises the possibility that pharmacological agents that increase NREM sleep can also stimulate GH secretion [13].

We have used chronic UAO in juvenile rats as a model bearing some features of human sleepdisordered breathing and subglottic stenosis $[14,15]$. In this model, we have shown that UAO
AFFLLIATIONS

*Sleep-Wake Disorders Unit, Soroka University Medical Center and Dept of Physiology,

\#Shraga Segal Dept of Microbiology and Immunology, Faculty of Health Sciences, Ben-Gurion University of the Negev, Beer-Sheva, Israel.

"These authors contributed equally to the study.

CORRESPONDENCE

A. Tarasiuk

Dept of Physiology, Faculty of Health

Sciences

Ben-Gurion University of the Negev

P.0. Box 105

Beer-Sheva 84105

Israel

E-mail: tarasiuk@bgu.ac.il

Received:

Dec 212010

Accepted after revision:

Jan 252011

First published online:

March 152011 
causes growth retardation, which is related to an impairment of the global and the local GH/insulin-like growth factor (IGF)-1 axis. In parallel, UAO also fragments NREM sleep [16].

The mechanisms linking UAO with neuroendocrine disturbances, which cause growth retardation and sleep abnormalities, are unknown. In this study, we hypothesised that UAO affects sleep and growth by causing a decrease in hypothalamic GHRH levels. We found that UAO indeed causes depletion of hypothalamic GHRH. We also provide evidence that pharmacological blockade of $5-\mathrm{HT}_{2}$ receptors could prevent the UAOinduced depletion of the hypothalamic GHRH content, preserve sleep and attenuate growth retardation.

\section{METHODS}

Further methods used can be found in the online supplementary material.

\section{Surgery}

Tracheal narrowing surgery (anaesthesia $200 \mathrm{mg} \cdot \mathrm{kg}^{-1}$ intraperitoneal tribromoethanol) was used to induce UAO in 22-day-old male Sprague-Dawley rats $[14,15]$. Controls underwent surgery with no tracheal narrowing. Animals were returned to their cages and kept in 12/12-h light/dark cycle, with lights on at 09:00 h. On day 9 , telemetric transmitters for sleep recording were implanted (see later). Food and water were provided ad libitum.

The study was approved by the Ben-Gurion University of the Negev Animal Use and Care Committee (Beer-Sheva, Israel) and complied with the American Physiological Society Guidelines.

\section{Experimental schedule}

Sleep was recorded on day 15 (baseline) and day 16 following acute administration of high-dose ritanserin (Sigma-Aldrich Ltd, Rehovot, Israel), a 5- $\mathrm{HT}_{2}$ receptor antagonist, at 09:00 h. In a separate series of animals, hypothalamic GHRH, GH receptor, GHRH receptor (GHRHR), orexin mRNA and proteins, serum GH and IGF-1 levels, and respiratory parameters were measured on day 15.

\section{Chronic ritanserin study}

In an additional series of experiments, UAO and control rats were treated with a high dose of ritanserin to stimulate SWS and $\mathrm{GH}$ secretion. Animals were injected intraperitoneally with ritanserin $\left(2 \mathrm{mg} \cdot \mathrm{kg}^{-1}\right)$ or vehicle at lights-on for eight consecutive days [15].

\section{Sleep}

Data were collected on day 16 (DSI, St Paul, MN, USA) and sleep signals were scored using software (NeuroScore version 2.1; DSI) and edited visually. The duration of sleep-wake states were calculated in 1-h time blocks [8] and were categorised as wake, SWS and paradoxical sleep (PS). Power density during the first $3 \mathrm{~h}$ of light was assessed separately for each vigilance state [17]. The power density values for $0.5-4.0 \mathrm{~Hz}$ were integrated and used as an index of electroencephalogram slowwave activity during NREM sleep [10]. The effect of ritanserin on slow-wave activity was calculated as the ratio of mean slow-wave activity obtained following ritanserin versus slowwave activity obtained at baseline [17].

\section{Hypothalamic mRNA expression}

RNA was extracted and quantitative real-time PCR assays were performed [15] for GHRH, GHRHR, GH receptor, orexin and $\beta$-actin. Total RNA from two animals was pooled and assayed as one sample, yielding eight combined samples in each group.

\section{Proteins}

Proteins were detected by Western blot $[14,15]$ in a subset of seven sham and eight UAO rats on day 16 .

\section{Immunoassays}

Serum GH and IGF-1 concentrations were measured using ELISA kits (DSL Inc., Webster, TX, USA) on day 16. Hypothalamic GHRH was determined by ELISA kit (USCN Life Science Inc., Wuhan, China) according to the manufacturer's instructions on day 16.

\section{Data analysis}

Significance was analysed by unpaired t-test. One-way ANOVA was used to determine significance differences in hypothalamic GHRH following administration of ritanserin or vehicle. Two-way ANOVA for repeated measures was used to determine significance between time and group, or frequency and group, for post hoc comparisons by Student-NewmanKuels test. The null hypotheses were rejected at the 5\% level.

\section{RESULTS}

Further results can be found in the online supplementary material.

A total of 117 animals were included in this study; the final numbers of animals were 55 and 50 for the UAO and sham control groups, respectively. During the surgical procedure, the mortality rate of the UAO group was $10 \%$ and an additional $10 \%$ mortality was observed $2-5$ days after surgery.

At days 13-16, the UAO rats' behaviour was similar to that of controls; they explored their cage and engaged in social activity, such as grooming. The UAO animals all demonstrated audible wheezing, especially after activity, but no signs of respiratory distress or gasping at rest were observed. As expected, following tracheal obstruction surgery, there were signs of increased mechanical load, i.e. inspiratory swings in oesophageal pressure $\left(P_{\mathrm{oes}}\right)$ more than doubled $(\mathrm{p}=0.03)$, respiratory rate decreased $(\mathrm{p}<0.001)$ and tracheal resistance $(\mathrm{n}=8$ in each group) increased by $46 \% \quad(\mathrm{p}=0.03)$ (online supplementary table 1E). Arterial blood gases and haemoglobin ( $n=8$ in each group) were normal and unchanged between groups (online supplementary table $1 \mathrm{E}$ ). The growth rate was significantly lower in UAO animals compared with controls $(\mathrm{n}=11$ in each group) (online supplementary table 2E). 13 days post-surgery, food intake was unchanged in the control $(n=10)$ and UAO $(n=11)$ rats (mean \pm SD $148 \pm 3.4$ and $164 \pm 6.9 \mathrm{~g}$ food per $\mathrm{kg}$ body weight, respectively; $\mathrm{p}=0.1$ ). Both the control $(n=8)$ and UAO groups $(n=8)$ exhibited circadian rhythms of body temperature. Mean \pm SEM 12-h light-period body temperature was $37.0 \pm 0.03$ and $36.5 \pm 0.03^{\circ} \mathrm{C}$ for the control and UAO rats, respectively $(\mathrm{p}<0.01)$. During the dark period, $12-\mathrm{h}$ body temperature was lower in UAO rats compared with controls $\left(37.0 \pm 0.04\right.$ and $37.5 \pm 0.04^{\circ} \mathrm{C}$, respectively; $\left.\mathrm{p}<0.01\right)$. 

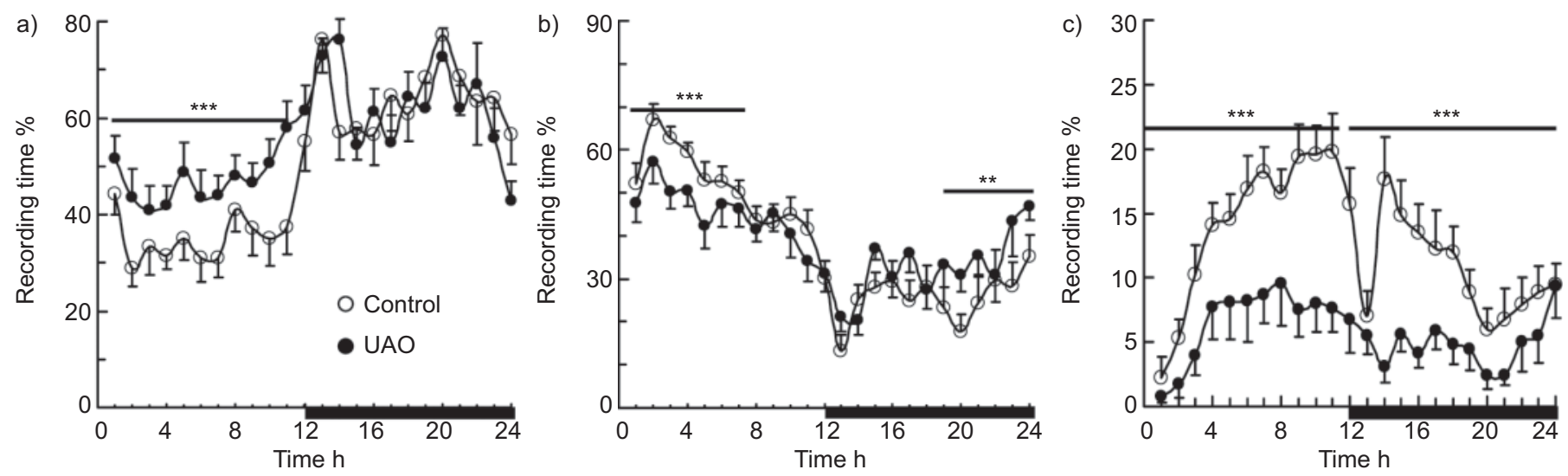

FIGURE 1. Spontaneous sleep in control and upper airway obstruction (UAO) rats. Hourly values of a) wake, b) slow-wave sleep (SWS) and c) paradoxical sleep (PS) are shown. Black horizontal bars represent the lights-off (active) period of a 12/12-h cycle with lights on at 09:00 h. UAO rats had significantly more wake, and less SWS and PS than controls during the light period. During the dark period, UAO rats had significantly more SWS and less PS than controls. Data are from 11 control and 11 UAO rats. Data are presented as mean \pm SEM. $* *: p<0.01 ; * * *: p<0.001$.

\section{Sleep duration}

Both the control $(n=11)$ and UAO $(n=11)$ rats exhibited circadian rhythms of wake, SWS and PS. As expected for nocturnal animals, there was more sleep in the light period than in the dark period (fig. 1). There were, however, several significant differences in sleep between UAO and control groups (fig. 1 and table 1). The UAO group was awake $36 \%$ more during the light period $(\mathrm{p}<0.001)$ and had $18 \%$ shorter SWS duration during the light period $(p<0.001)$. UAO rats had significant elevation of light SWS (SWS-1) and reduction of deep SWS (SWS-2), compared with controls, during the first $6 \mathrm{~h}$ of the light period $(\mathrm{p}<0.01)$. Interestingly, during the dark period, UAO animals had $38.3 \%$ more SWS than controls $(p<0.001)$. Obstructed animals had $41 \%$ less PS $(p<0.001)$ than controls during both light and dark periods (fig. 1 and table 1).

To determine the total duration of each sleep-wake stage, we quantified the number and length of each sleep stage epoch (fig. 2) for the 12-h light periods. UAO animals had more frequently interrupted sleep compared with controls. The obstructed group had 35\% more wake bouts and these were $67 \%$ longer than in controls $(\mathrm{p}<0.001)$. UAO rats manifested a $37 \%$ reduction in the number of SWS bouts $(p<0.01)$ without any change in duration, and a $50 \%$ decrease in the number of bouts and duration of PS $(\mathrm{p}<0.001)$.

\section{Power density analysis}

During SWS, the power density of UAO rats $(n=11)$ decreased by $40 \%$ at $1.5 \mathrm{~Hz}$ compared with controls $(n=11)$ (online supplementary fig. $1 \mathrm{E} ; \mathrm{p}<0.001)$. Spectral analysis showed that SWS-1 and SWS-2 decreased by 37 and 57\%, respectively, in the UAO group during the first $3 \mathrm{~h}$ of the light period, in the frequency range of $0.5-4 \mathrm{~Hz}$, compared with controls (data not shown; $p<0.001)$. The time-course of electroencephalogram slow-wave activity during NREM sleep showed a normal pattern in the controls, with high slow-wave activity values at the beginning of the rest period followed by a decline towards dark onset and a gradual increase during the dark period (fig. 3). In contrast, the daily course of electroencephalogram slow-wave activity was flat in UAO rats; there were no significant changes detected in slow-wave activity depth over the course of the day $(\mathrm{p}<0.001)$.

\section{Ritanserin study}

Acute administration of the a high dose of the $5-\mathrm{HT}_{2}$ receptor antagonist ritanserin significantly decreased $(p<0.01)$ wake duration during lights-on in UAO rats $(n=10$ in each group) to levels statistically similar to those of controls (fig. 4). In both groups, ritanserin significantly increased SWS duration $\leqslant 6 \mathrm{~h}$ following drug administration; this was related to elevation of SWS-2 duration (fig. 4 and table 1). Ritanserin increased slowwave activity $\leqslant 6 \mathrm{~h}$ following drug administration in both groups ( $<<0.01$; fig. 3b). Confirming earlier reports [15], during the chronic ritanserin study, growth gain parameters were $\sim 50 \%$ lower $(p<0.001)$ in UAO rats $(n=12)$ compared with controls $(n=10)$. Ritanserin partially normalised somatic growth retardation, as revealed by tail and tibial lengths, but not body weight gain (fig. 5). UAO decreased serum IGF-1 in rats treated with vehicle (mean $\pm \mathrm{SEM} 700 \pm 80 \mathrm{ng} \cdot \mathrm{mL}^{-1}$ ) compared to UAO

\begin{tabular}{|c|c|c|c|c|}
\hline \multirow[t]{3}{*}{ TABLE 1} & \multicolumn{4}{|c|}{$\begin{array}{l}\text { Spontaneous sleep values during 12-h lights-on } \\
\text { period }\end{array}$} \\
\hline & \multicolumn{2}{|c|}{ Control $^{\#}$} & \multicolumn{2}{|c|}{ UAO $^{\#}$} \\
\hline & Baseline & Ritanserin & Baseline & Ritanserin \\
\hline Wake & $38.9 \pm 2.3$ & $33.6 \pm 2.2$ & $52.9 \pm 2.6^{\star \star}$ & $41.1 \pm 2.3^{\star \star \star}$ \\
\hline sws & $45.3 \pm 1.6$ & $52.0 \pm 1.9^{\star \star \star}$ & $37.1 \pm 2.6^{\star \star}$ & $48.7 \pm 1.8^{\star \star \star}$ \\
\hline PS & $15.7 \pm 1.8$ & $14.6 \pm 0.8$ & $9.2 \pm 1.2^{\star *}$ & $10.6 \pm 1.0^{\star \star \star}$ \\
\hline SWS-1 & $31.8 \pm 1.0$ & $31.1 \pm 0.9$ & $29.1 \pm 2.2$ & $29.2 \pm 1.5$ \\
\hline SWS-2 & $13.7 \pm 1.3$ & $21.0 \pm 2.1 * * *$ & $8.4 \pm 2.2^{\star \star}$ & $19.0 \pm 1.4^{\star \star \star}$ \\
\hline \multicolumn{5}{|c|}{$\begin{array}{l}\text { Data are presented as mean } \pm \text { SEM } \% \text { of time spent in each sleep stage for the } \\
\text { light period (09:00-21:00 h). UAO: upper airway obstruction; SWS: short-wave } \\
\text { sleep; PS: paradoxical sleep; SWS-1: light SWS; SWS-2: deep SWS (stages } 3-4 \\
\text { in humans). }{ }^{\#}: \mathrm{n}=10 .{ }^{* *}: \mathrm{p}<0.01 \text { comparing baseline (vehicle) control with } \\
\text { baseline (vehicle) UAO by two-way ANOVA; }{ }^{* * *}: \mathrm{p}<0.001 \text { comparing ritanserin } \\
\left(2 \mathrm{mg} \cdot \mathrm{kg}^{-1} \text { ) with baseline (vehicle) by two-way ANOVA. }\right.\end{array}$} \\
\hline
\end{tabular}



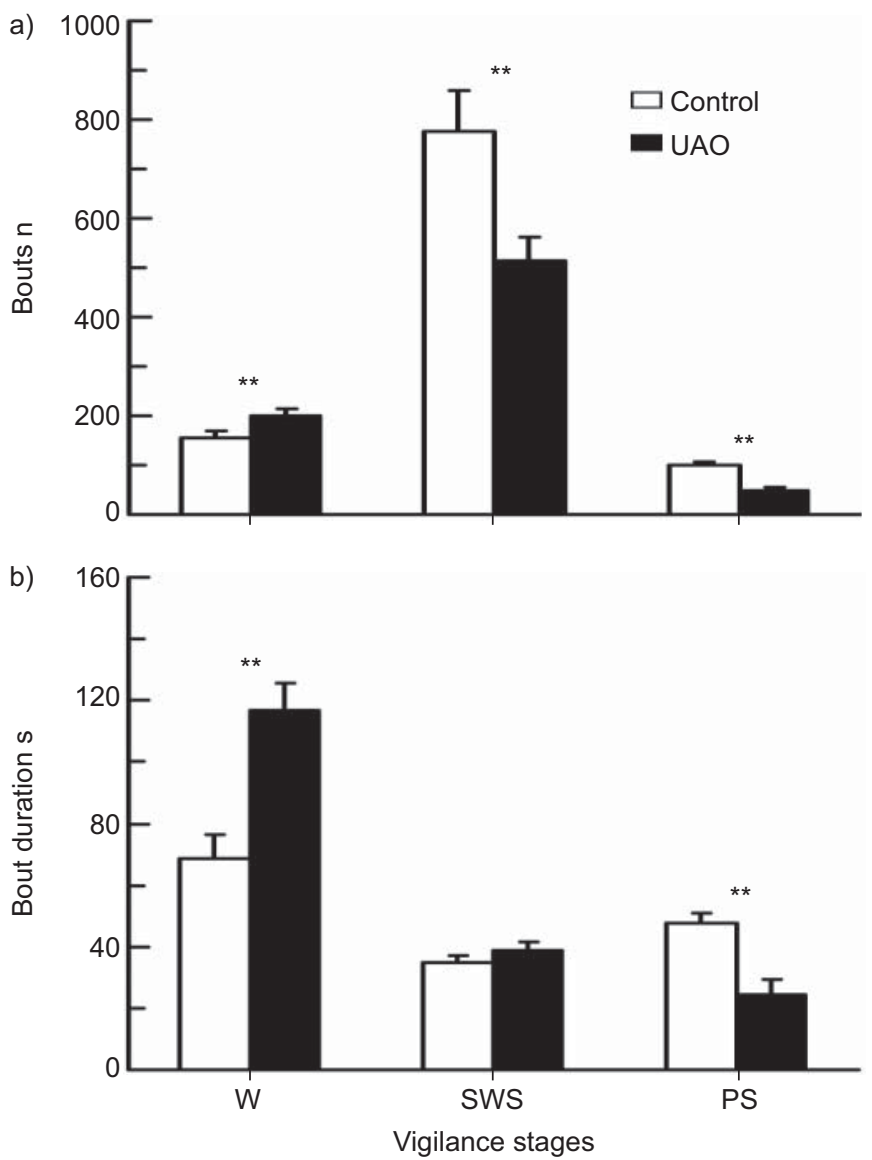

FIGURE 2. a) Total number and b) duration of each sleep-wake stage during the 12-h lights-on period. Data are presented as mean \pm SEM. W: wake; SWS: slowwave sleep; PS: paradoxical sleep; UAO: upper airway obstruction. ${ }^{*}$ : $p<0.01$.

treated with vehicle $\left(550 \pm 50 \mathrm{ng} \cdot \mathrm{mL}^{-1}\right)(\mathrm{p}=0.01)$. Ritanserin normalised this effect on serum IGF-1 values $\left(680 \pm 90 \mathrm{ng} \cdot \mathrm{mL}^{-1}\right.$; not significantly different from the control group).

\section{Endocrine analysis}

Endocrine analysis was performed in a subset of 10 sham and 12 UAO rats: serum GH $\left(101 \pm 8 \mathrm{ng} \cdot \mathrm{mL}^{-1}\right.$ in control and $62 \pm 5 \mathrm{ng} \cdot \mathrm{mL}^{-1}$ in UAO rats; $\left.\mathrm{p}=0.038\right)$ and IGF-1 level $\left(1,400 \pm 86 \mathrm{ng} \cdot \mathrm{mL}^{-1}\right.$ in control and $870 \pm 60 \mathrm{ng} \cdot \mathrm{mL}^{-1}$ in UAO rats; $\mathrm{n}=9 ; \mathrm{p}=0.001$ ) were significantly reduced in UAO. Hypothalamic GHRH mRNA (fig. 6a) and protein (fig. 6b) decreased in UAO animals by $30 \%(p=0.002)$ and $25 \%(p=0.001)$, respectively. Hypothalamic GHRHR protein decreased by $72 \%$ in UAO animals $(p=0.001)$ (fig. $6 c)$. Administration of ritanserin for 8 days at lights-on normalised hypothalamic GHRH content in UAO animals (controls $1.6 \pm 0.29$ pg GHRH per $\mathrm{mg}$ tissue; UAO animals $1.5 \pm 0.19 \mathrm{pg}$ GHRH per mg tissue; $p=0.327$, one-way ANOVA; $n=10$ in each group). Hypothalamic orexin mRNA increased by $73 \%$ in UAO animals $(p<0.01)$ (online supplementary fig. 3E).

\section{DISCUSSION}

We have shown that growth retardation in UAO is associated with reduction of hypothalamic GHRH content, which could explain both the abnormal SWS and impaired GH homeostasis
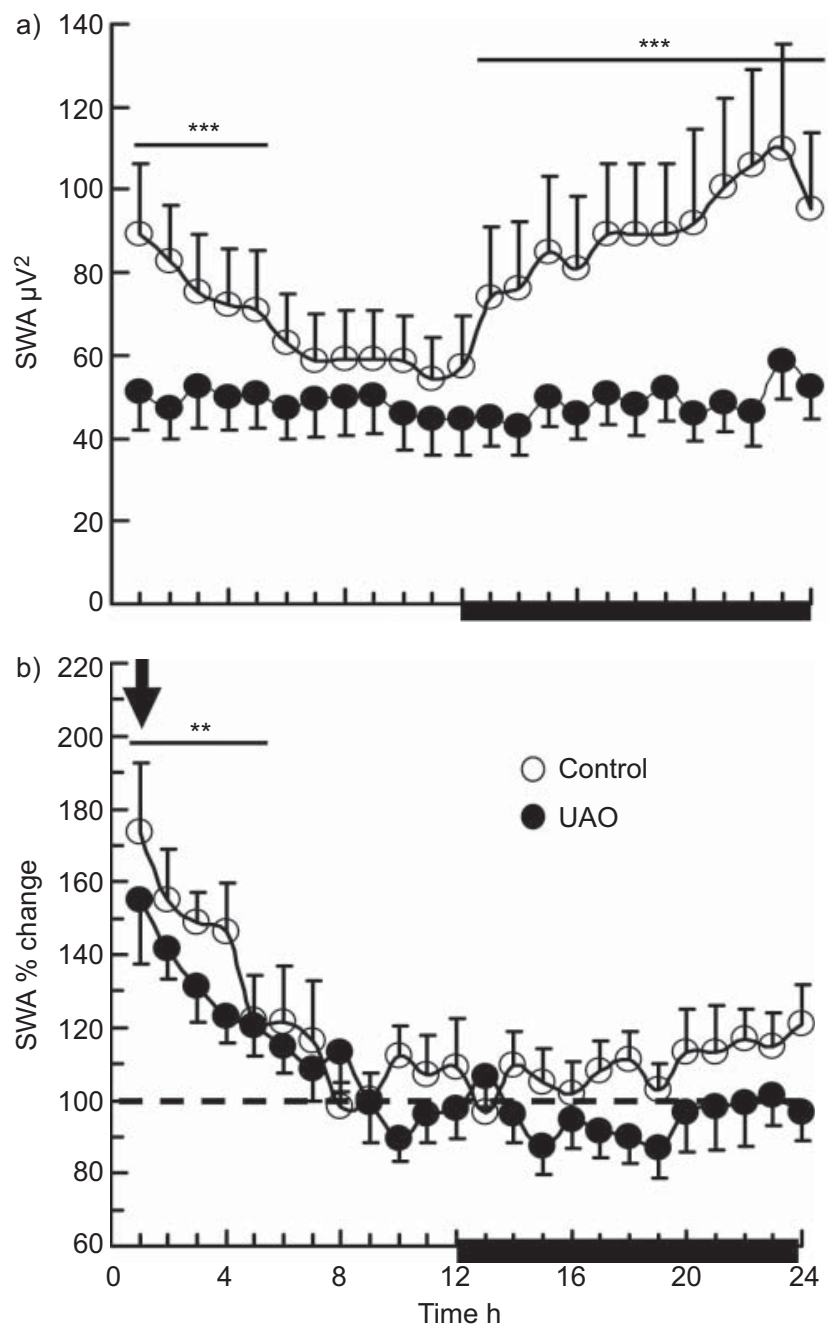

FIGURE 3. a) Hourly average of electroencephalogram slow-wave activity (SWA; integrated power densities in delta range). SWA was significantly lower in upper airway obstruction (UAO) rats compared with controls. b) Effect of ritanserin $\left(2 \mathrm{mg} \cdot \mathrm{kg}^{-1}\right.$ ) on SWA calculated as percentage of baseline values on day 15 (arrow identifies time of injection). Black horizontal bars represent lights-off on a 12/12-h cycle with lights on at 09:00 h. Data are presented as mean \pm SEM. ${ }^{* *}: p<0.01$ following ritanserin relative to baseline vehicle values on day 15 in both groups; $* * *: p<0.001$ between groups.

in juvenile UAO rats. Our data suggest that a similar mechanism could be responsible for growth retardation of children suffering from UAO without preserved sleep architecture.

It is not clear why growth retardation occurs only in $5-25 \%$ of children with sleep-disordered breathing [1-4]. Several controversial mechanisms have been suggested to explain this phenomenon: dysphagia and decreased appetite [4], increased work of breathing during sleep [3], and abnormal GH homeostasis [1, 2]. In this study, we offer the suggestion of the involvement of an impaired GH axis as a major mechanism of growth retardation. In contrast to our UAO rats, children with UAO typically do not have an elevated arousal index secondary to obstructive events and have preserved sleep stage durations [18]. Our results may suggest that growth retardation may occur in a subset of children without preserved sleep architecture. 


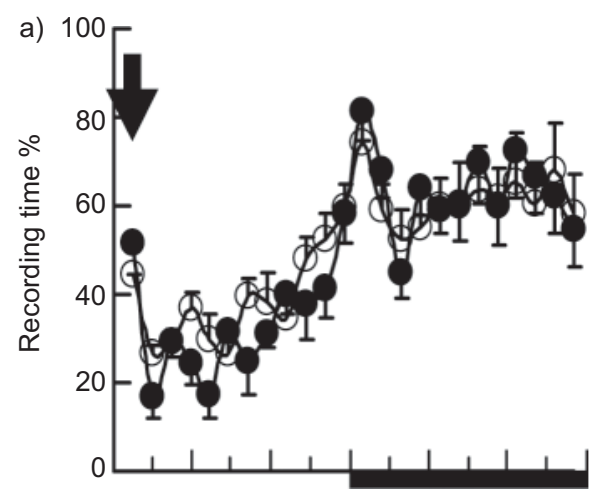

b)
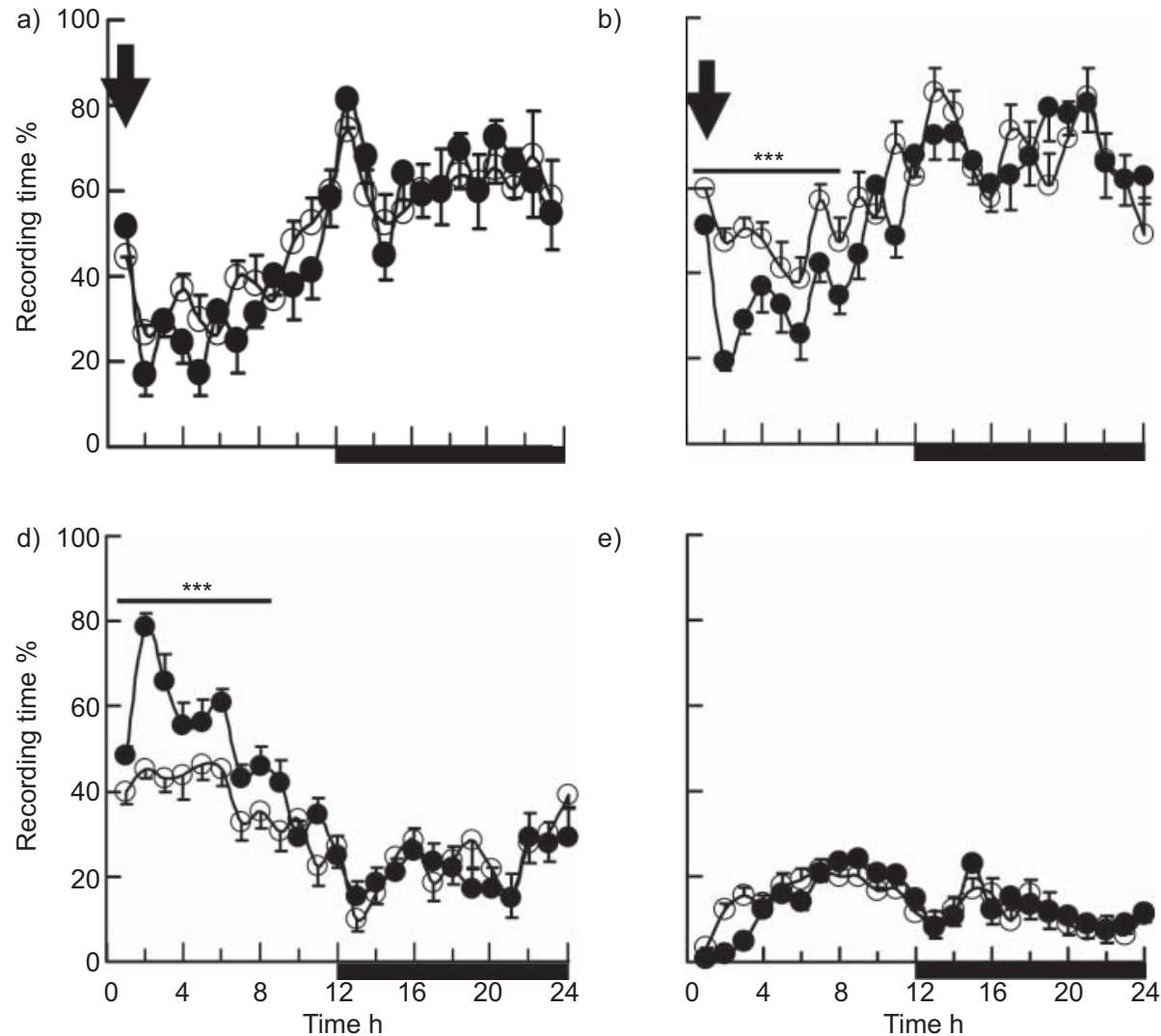

e)

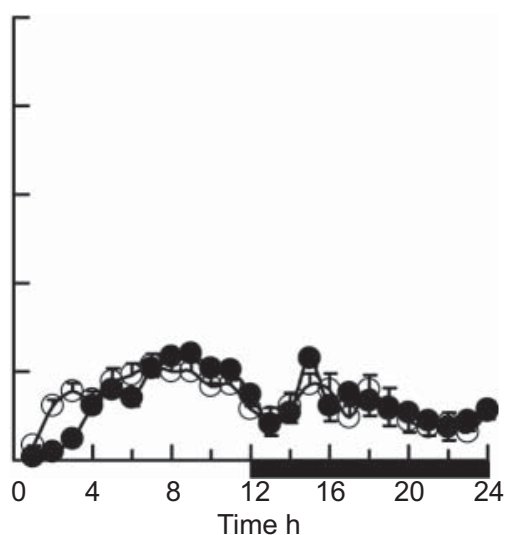

c)

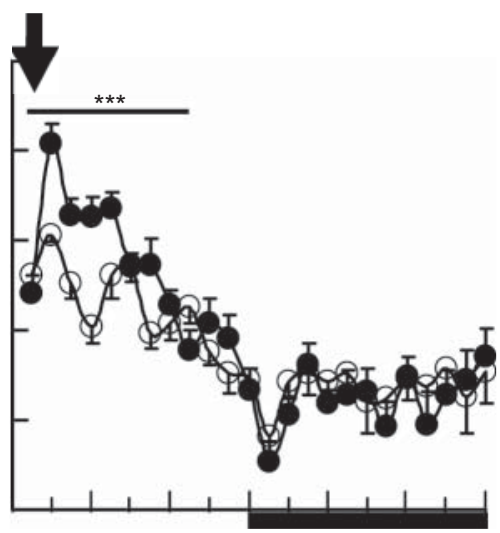

f)

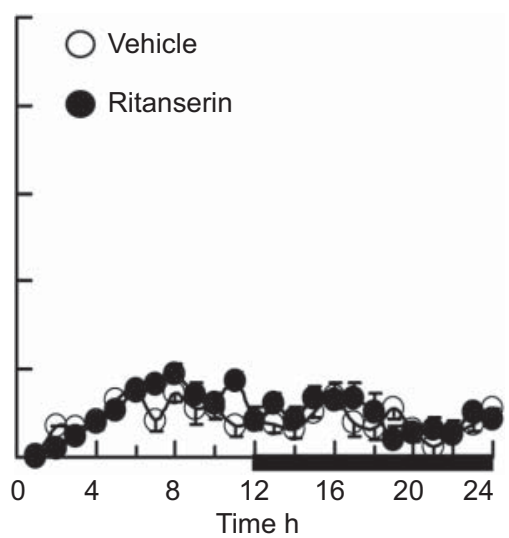

FIGURE 4. Effect of ritanserin (2 $\left.\mathrm{mg} \cdot \mathrm{kg}^{-1}\right)$ on spontaneous sleep. Hourly values of a, b) wake, c, d) slow-wave sleep and e, f) paradoxical sleep are shown in a, c, e) control and b, d, f) upper airway obstruction rats. Ritanserin (2 $\mathrm{mg} \cdot \mathrm{kg}^{-1}$; baseline: day 16) or vehicle (baseline: day 12) was administered at lights-on (arrow). Black horizontal bars represent the lights-off (active) period in a 12/12-h cycle with lights on at 09:00 h. Data are presented as mean \pm SEM. ***: $p<0.001$ between vehicle and ritanserin values.

We have also shown that pharmacological correction of the abnormalities in the GHRH/GH axis may potentially be a promising strategy for therapeutic interventions designed to improve growth in affected children.

\section{Strengths and limitations of the model}

Chronic upper airway loading was induced in 22-day-old rats and animals were followed for 2 weeks, a period comparable to 6 months to 8 yrs of age in children. Following surgery, inspiratory swings in Poes and tracheal resistance increased, consistent with increased airway resistive loading. Previously, we demonstrated that UAO led to a decreased respiratory rate and tidal volume accompanied by mild elevation of arterial carbon dioxide tension $\left(\mathrm{PCO}_{2}\right)[15,19]$. Because our measurements of Poes were taken under anaesthesia, they may underestimate the true effects of obstruction on intrathoracic pressure. The unchanged $\mathrm{PCO}_{2}$, and reduced respiratory rate and Poes in the current study suggest that the trachea was not
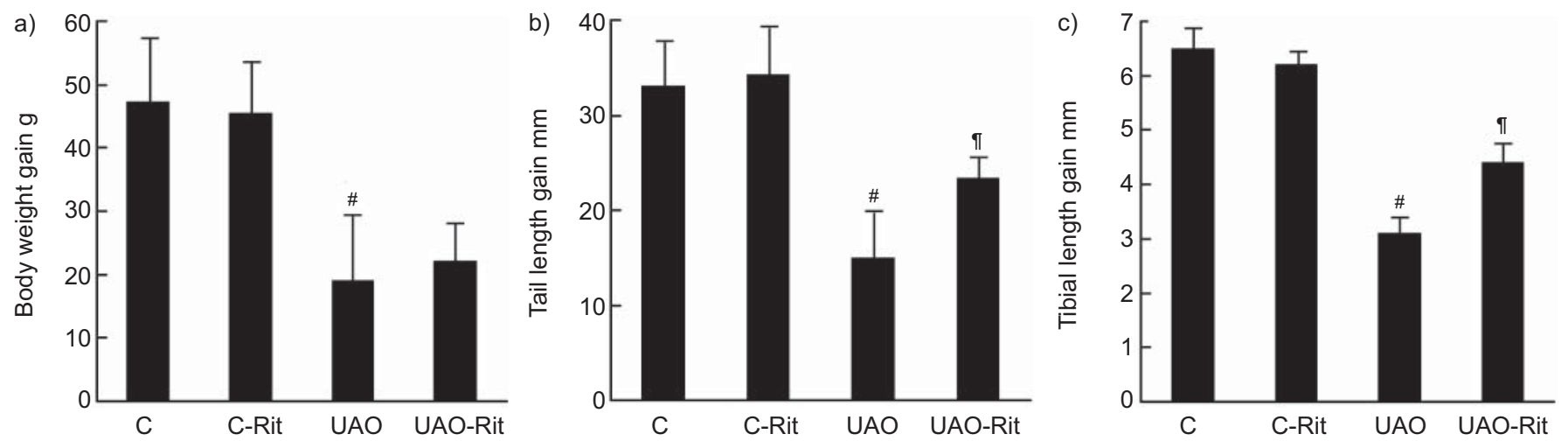

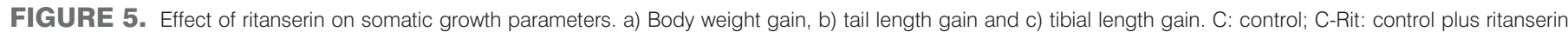

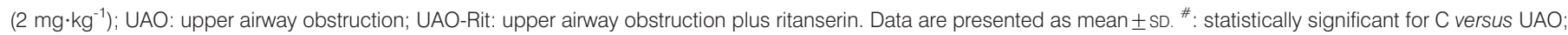
?: statistically significant for UAO versus UAO-Rit. 

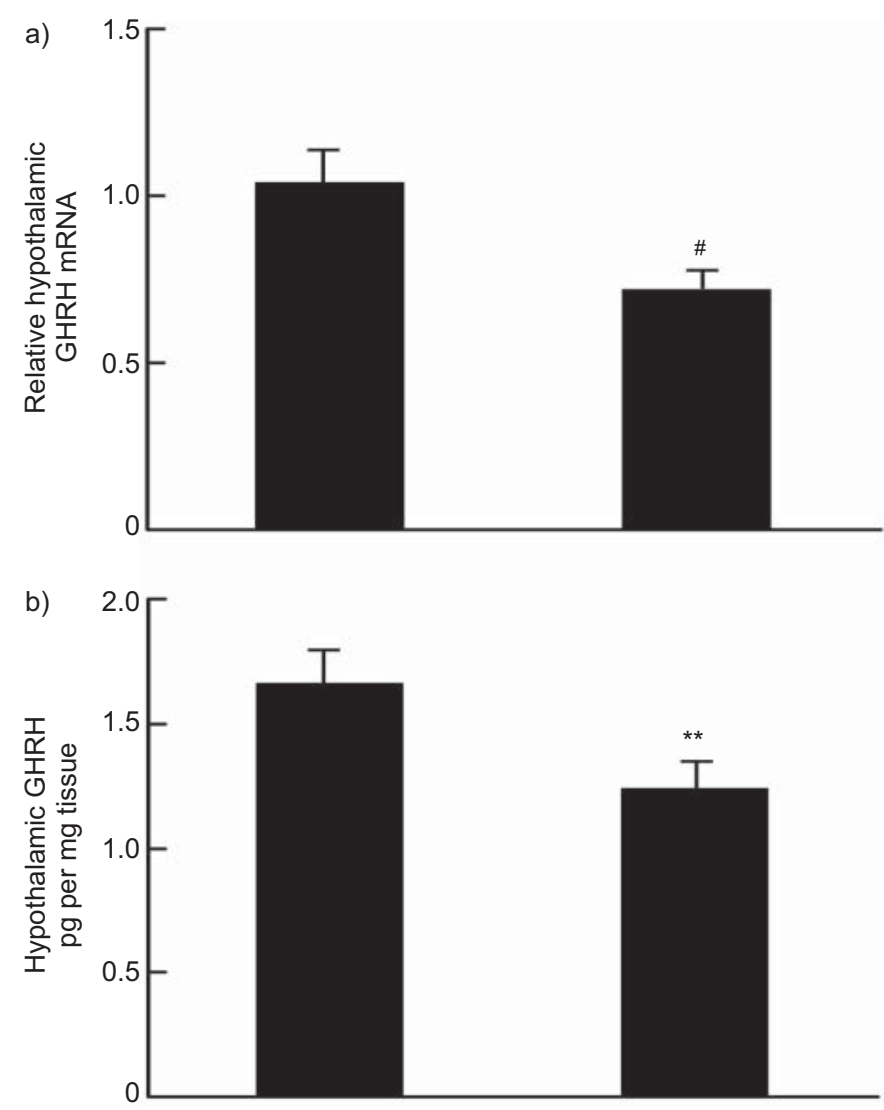

c)
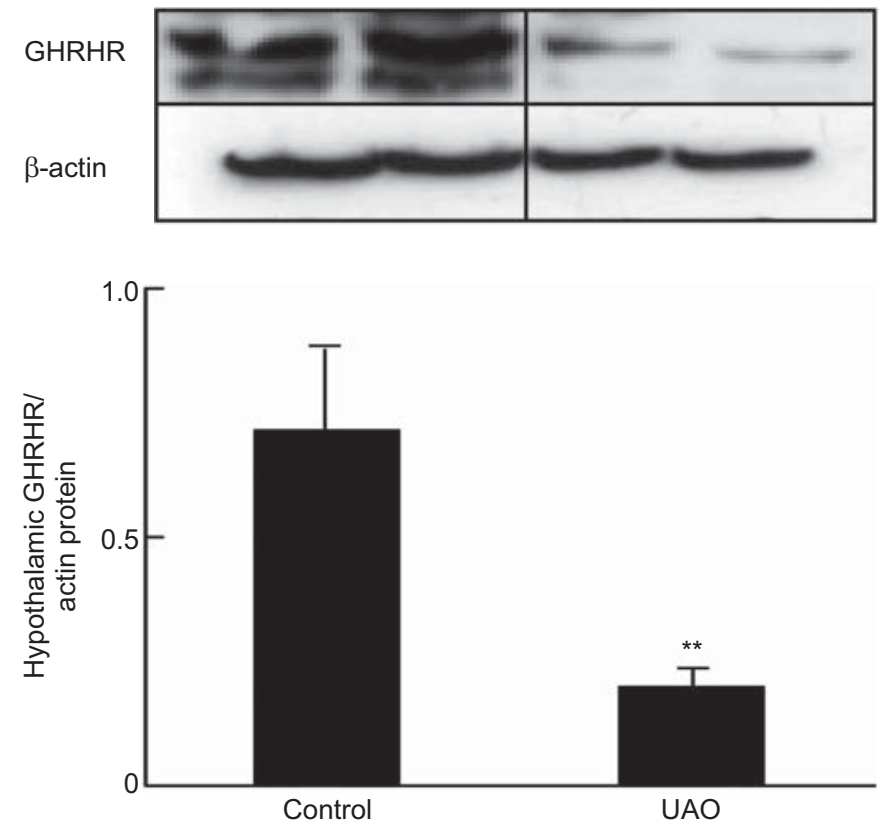

FIGURE 6. a) Relative hypothalamic growth hormone-releasing hormone (GHRH) mRNA level determined by real-time PCR. b) Hypothalamic GHRH content, determined by ELISA. c) Representative Western blot analysis of hypothalamic GHRH receptor (GHRHR) and densitometric analysis of GHRHR protein. UAO upper airway obstruction. ${ }^{*}: p=0.002 ;{ }^{*}: p=0.01$. severely obstructed and could be considered typical for mildto-moderate respiratory loading. Under these conditions, animals were able to maintain normal resting ventilation and arterial oxygen tension [14, 15, 19]. In children, however, oxygen saturation usually decreases with airway loading during sleep [20]. The UAO model has been used to explore adaptive changes in respiratory system function $[14,15,19,21$, 22]. In this model, both inspiratory and expiratory loading were introduced, which may resemble subglottic stenosis in children and not be exclusively sleep related, while in clinical sleep-disordered breathing, airway loading is mainly inspiratory and sleep related [18]. Obstructive sleep apnoea is associated with intermittent UAO at night, primarily during inspiration. It seems likely that our model also has implications for this condition since, as in sleep apnoea, the animals exhibited sleep fragmentation and, as in children with sleep apnoea, the animals showed growth retardation.

Ritanserin treatment normalised the GH axis and growth parameters were partially restored. This finding may suggest that, in addition to $\mathrm{GH}$ and GHRH, other mechanisms may also be involved in growth retardation in this model. It is possible that there is impairment of total body energy balance related to increased work of breathing [3] and/or increased energy expenditure due to enhanced locomotion activity due to the sleep fragmentation. There is little evidence to support these possibilities, as total body energy in UAO rats during quiet wakefulness was similar to that in controls [14]. Mean locomotor activity in UAO rats was unchanged or even decreased during active and quiet phases of the day, respectively [15]. Finally, protein loss and cachexia may have been induced following increased production of oxygenderived free radicals and cytokines, as a result of strenuous contractions of respiratory muscles associated with upper airway loading [23]. However, previous studies have not found changes in serum pro-inflammatory factors, such as interleukin-6 and tumour necrosis factor- $\alpha$, in UAO rats [24].

\section{UAO and GHRH/GH axis}

Chronic UAO inhibited the secretion of hypothalamic GHRH in our model. Hypothalamic GHRH is necessary to maintain GHRHR synthesis and both GH and GHRH regulate their own synthesis by negative feedback at the level of the hypothalamus $[9,25-27]$. In order to better understand the distribution and localisation of GHRH and GHRHR in specific hypothalamic nuclei, future studies should be performed using immunocytochemical staining. In our study, PS was significantly reduced in UAO rats. PS deprivation can significantly decrease GHRH mRNA in the paraventricular and arcuate nuclei [28].

Orexins/hypocretins are neuropeptides inhibiting GHRH in hypothalamic nuclei involved in NREM and rapid eye movement sleep regulation [29]. In UAO rats, orexin mRNA increased by $73 \%$, possibly as a result of forced physical activity [21] and/or increased awakening [30]. Interestingly, the neuroendocrine effects that we observed in UAO rats resemble those seen following prolonged sleep-deprivation/ restriction in rats, including decreased body temperature [31], depletion of hypothalamic GHRH content [7, 8] and reduction of serum GH [32]. It is possible that sleep fragmentation due to $\mathrm{UAO}$ leads to orexin increase and abnormal serotonergic 
balance, which results in reduced SWS and GHRH [29]. Further studies are needed to explore this issue.

The strong association between NREM sleep and GH release raises the possibility that pharmacological agents that increase NREM sleep can also stimulate $\mathrm{GH}$ secretion [13]. In the current study, hypothalamic GHRH/GH axis and sleep in $\mathrm{UAO}$ rats were reversed by administration of ritanserin. Stimulation of GH secretion and promotion of sleep are two closely interrelated outputs of hypothalamic GHRHergic neurons [9]. As in our study, administration of a high dose of ritanserin had a strong sleep consolidation effect in rats [33] and in humans with pre-existing sleep fragmentation [34]. This could provide additional explanation for the improved sleep duration and slow-wave activity following ritanserin administration in UAO. Finally, similarly to other reports [33, 35], the effects of ritanserin on SWS and wake cycles are limited to the first hours of light onset following drug administration due to its known pharmacokinetics.

We found that decreased GHRH was associated with both sleep and growth impairment. This is consistent with studies showing that sleep duration and depth are suppressed when GHRH is inhibited by means of a competitive GHRHR antagonist, activation of the negative feedback in the somatotropic axis or after somatostatinergic stimulation [7, 8]. Slowwave activity is also regulated, in part, via intrinsic cortical GHRH [36]. Slow-wave activity increases during wakefulness, due to cortical and motor activities during awakening, and declines during sleep [37]. Indeed, consistent with this, our UAO rats spent significantly more time in SWS (fig. 1b) during the dark phase and were less active during the dark phase [15]. Further studies are needed to explore the role of cortical GHRH in juvenile UAO rats.

Several possibilities may explain the reduction of PS in our UAO rats. During PS, the skeletal muscle force is minimal and insufficient to support ventilation during chronic resistive loading, and the arousal threshold to acoustic stimulation is lower [38], resulting in shortening of this stage in our rats. Our UAO animals had lower GH levels. Rats with impairment in GHRH signalling have less PS than normal rats [39].

\section{Conclusion}

This study presents evidence that growth retardation in UAO is associated with a reduction in hypothalamic GHRH content. Our findings show that the abnormalities in the GHRH/GH axis underlie both growth retardation and SWS-disorder UAO.

\section{SUPPORT STATEMENT}

This study was supported by the Israel Science Foundation (grant number 160/10).

\section{STATEMENT OF INTEREST}

None declared.

\section{REFERENCES}

1 Bar A, Tarasiuk A, Segev Y, et al. The effect of adenotonsillectomy on serum insulin-like growth factor-I and growth in children with obstructive sleep apnea syndrome. J Pediatr 1999; 135: 76-78.
2 Bonuck KA, Freeman K, Henderson J. Growth and growth biomarker changes after adenotonsillectomy: systematic review and meta-analysis. J Arch Dis Child 2009; 94: 83-91.

3 Marcus CL, Carroll JL, Koerner CB, et al. Determinants of growth in children with the obstructive sleep apnea syndrome. J Pediatr 1994; 125: 556-562.

4 Stradling JR, Thomas G, Warley AR, et al. Effect of adenotonsillectomy on nocturnal hypoxaemia, sleep disturbance, and symptoms in snoring children. Lancet 1990; 335: 249-253.

5 Van Cauter E, Kerkhofs M, Caufriez A, et al. A quantitative estimation of growth hormone secretion in normal man: reproducibility and relation to sleep and time of day. J Clin Endocr Metab 1992; 74: 1441-1450.

6 Steiger A, Guldner J, Hemmeter U, et al. Effects of growth hormone-releasing hormone and somatostatin on sleep EEG and nocturnal hormone secretion in male controls. Neuroendocrinology 1992; 56: 566-573.

7 Obal F Jr, Payne L, Kapás L, et al. Inhibition of growth hormonereleasing factor suppresses both sleep and growth hormone secretion in the rat. Brain Res 1991; 557: 149-153.

8 Zhang J, Obal F Jr, Zheng T, et al. Intrapreoptic microinjection of GHRH or its antagonist alters sleep in rats. J Neurosci 1999; 19: 2187-2194.

9 Obal F Jr, Krueger JM. GHRH and sleep. Sleep Med Rev 2004; 8: 367-377.

10 Ben-Israel N, Zigel Y, Tal A, et al. Adenotonsillectomy improves slow-wave activity in children with obstructive sleep apnoea. Eur Respir J 2011; 37: 1144-1150.

11 Heinzer R, Gaudreau H, Decary A, et al. Slow-wave activity in sleep apnea patients before and after continuous positive airway pressure treatment: contribution to daytime sleepiness. Chest 2001; 119: 1807-1813.

12 Guilleminault C, Kirisoglu C, da Rosa AC, et al. Sleepwalking, a disorder of NREM sleep instability. Sleep Med 2006; 7: 163-170.

13 Gronfier C, Luthringer R, Follenius $\mathrm{M}$, et al. A quantitative evaluation of the relationships between growth hormone secretion and delta wave electroencephalographic activity during normal sleep and after enrichment in delta waves. Sleep 1996; 19: 817-824.

14 Tarasiuk A, Segev Y. Chronic upper airway resistive loading induces growth retardation via the GH/IGF-1 axis in prepubescent rats. J Appl Physiol 2007; 102: 913-918.

15 Segev Y, Berdugo-Boura N, Porati O, et al. Upper airway loading induces growth retardation and change in local chondrocyte IGF-I expression is reversed by stimulation of $\mathrm{GH}$ release in juvenile rats. J Appl Physiol 2008; 105: 1602-1609.

16 Tarasiuk A, Berdugo-Boura N, Segev Y. Growth and sleep impairment are associated with decreased hypothalamic growth hormone releasing hormone in chronic upper airway loading in juvenile rats. Sleep 2010; 33: A18.

17 Kantor S, Jakus R, Balogh B, et al. Increased wakefulness, motor activity and decreased theta activity after blockade of the $5-\mathrm{HT}_{2 \mathrm{~B}}$ receptor by the subtype-selective antagonist SB-215505. $\mathrm{Br} \mathrm{J}$ Pharmacol 2004; 142: 1332-1342.

18 Arens R, Marcus CL. Pathophysiology of upper airway obstruction: a developmental perspective. Sleep 2004; 27: 997-1019.

19 Greenberg HE, Tarasiuk A, Rao RS, et al. Effect of chronic resistive loading on ventilatory control in a rat model. Am J Respir Crit Care Med 1995; 152: 666-676.

20 Pillar G, Schnall RP, Peled N, et al. Impaired respiratory response to resistive loading during sleep in healthy offspring of patients with obstructive sleep apnea. Am J Respir Crit Care Med 1997; 155: 1602-1608.

21 Tarasiuk A, Scharf SM, Miller MJ. Effect of chronic resistive loading on inspiratory muscles in rats. J Appl Physiol 1991; 70: 216-222.

22 Salejee I, Tarasiuk A, Reder I, et al. Chronic upper airway obstruction produces right but not left ventricular hypertrophy in rats. Am Rev Respir Dis 1993; 148: 1346-1350.

23 Reid WD, Belcastro AN. Chronic resistive loading induces diaphragm injury and ventilatory failure in the hamster. Respir Physiol 1999; 118: 203-218. 
24 Tarasiuk A, Segev Y. Chronic resistive airway loading reduces weight due to low serum IGF-1 in rats. Respir Physiol Neurobiol 2005; 145: 177-182.

25 Aleppo G, Moskal SF 2nd, De Grandis PA, et al. Homologous down-regulation of growth hormone-releasing hormone receptor messenger ribonucleic acid levels. Endocrinology 1997; 138: 1058-1065.

26 Horikawa R, Hellmann P, Cella SG, et al. Growth hormonereleasing factor (GRF) regulates expression of its own receptor. Endocrinology 1996; 137: 2642-2645.

27 Chomczynski P, Downs TR, Frohman LA. Feedback regulation of growth hormone (GH)-releasing hormone gene expression by $\mathrm{GH}$ in rat hypothalamus. Mol Endocrinol 1988; 2: 236-241.

28 Toppila J, Asikainen M, Alanko L, et al. The effect of REM sleep deprivation on somatostatin and growth hormone-releasing hormone gene expression in the rat hypothalamus. J Sleep Res 1996; 5: 115-122.

29 Lopez M, Nogueiras R, Tena-Sempere M, et al. Orexins (hypocretins) actions on the GHRH/somatostatin-GH axis. Acta Physiol 2010; 198: 325-334.

30 de Lecea L, Sutcliffe JG. The hypocretins and sleep. FEBS J 2005; 272: 5675-5688.

31 Rechtschaffen A, Bergmann BM. Sleep deprivation in the rat: an update of the 1989 paper. Sleep 2002; 25: 18-24.
32 Everson CA, Crowley WR. Reductions in circulating anabolic hormones induced by sustained sleep deprivation in rats. Am J Physiol Endocrinol Metab 2004; 286: E1060-E1070.

33 Kirov R, Moyanova S. Age-related effect of ritanserin on the sleepwaking phases in rats. Int J Neurosci 1998; 93: 265-278.

34 Viola AU, Brandenberger G, Toussaint M, et al. Ritanserin, a serotonin-2 receptor antagonist, improves ultradian sleep rhythmicity in young poor sleepers. Clin Neurophysiol 2002; 113: 429-434.

35 Kantor S, Jakus R, Bodizs R, et al. Acute and long-term effects of the $5-\mathrm{HT}_{2}$ receptor antagonist ritanserin on EEG power spectra, motor activity, and sleep: changes at the light-dark phase shift. Brain Res 2002; 943: 105-111.

36 Szentirmai E, Yasuda T, Taishi P, et al. Growth hormone-releasing hormone: cerebral cortical sleep-related EEG actions and expression. Am J Physiol Regul Integr Comp Physiol 2007; 293: R922-R930.

37 Huber R, Ghilardi MF, Massimini M, et al. Arm immobilization causes cortical plastic changes and locally decreases sleep slow wave activity. Nat Neurosci 2006; 9: 1169-1176.

38 Neckelmann D, Ursin R. Sleep stages and EEG power spectrum in relation to acoustical stimulus arousal threshold in the rat. Sleep 1993; 16: 467-477.

39 Obal F Jr, Fang J, Taishi P, et al. Deficiency of growth hormonereleasing hormone signaling is associated with sleep alterations in the dwarf rat. J Neurosci 2001; 21: 2912-2918. 